\title{
Increase of bending fatigue resistance for tungsten inert gas welded SS400 steel plates using friction stir processing
}

\author{
Kazuhiro Ito*, Tatsuya Okuda, Rintaro Ueji, Hidetoshi Fujii and Chiaki Shiga \\ Joining and Welding Research Institute, Osaka University, 11-1 Mihogaoka, Ibaraki, Osaka 567-0047, Japan \\ *Corresponding author: Phone Num.: +81-6-6879-8659, E-mail: ito@jwri.osaka-u.ac.jp
}

\begin{abstract}
To improve the fatigue resistance of tungsten inert gas (TIG)-welded SS400 steel plates, friction stir processing (FSP) was performed on TIG weld beads. Although the tensile properties of the TIG-welded steel plates with FSP were similar to those without FSP, their bending strength exhibited about $1.4 \mathrm{GPa}$ at room temperature, which was $40 \%$ higher than that without FSP (about $1 \mathrm{GPa}$ ). Similarly, FSP produced about $170 \%$ increase in the number of cycles to failure at an applied stress amplitude of $270 \mathrm{MPa}$ during three-point bending fatigue at room temperature. A fine-grained FSP region (grain sizes of about 1-2 $\mu \mathrm{m}$ in diameter) enhanced grain-boundary strengthening, leading to the higher bending strength and bending fatigue resistance.
\end{abstract}

Keywords: Structural steel; Tungsten inert gas; Friction stir processing; bending fatigue 


\section{Introduction}

Friction stir processing (FSP) is based on the principle of friction stir welding (FSW), and provides a significant grain refinement and homogenization that had previously been obtained mainly in light alloys [1-4]. The microstructural modification by FSP increased hardness of AZ31 magnesium alloy [2] and tensile strength of ADC12 aluminum die casting alloy [4]. FSP is also an effective surface-microstructural modification technique used to extend fatigue life of weld joints, as are re-melting, hammering, and blasting for aluminum alloys, for example metal inert gas butt welds performed on AA6082-T6 [5] and 5082-H321/5356 aluminum gas metal arc welds [6].

However, the FSP technique has not yet been applied to weld joints of steel plates for the purpose of optimizing the surface strength and fatigue performance. The fatigue strength of weld joints is much lower than that of the base metals, and thus various surface treatment techniques such as ultrasonic peening [7-11], laser peening [12], shot peening [13-18], and hammer peening $[19,20]$, have been studied as means for improving fatigue strength of the weld joints. Although the application of FSW to steels and other high-temperature materials has been limited due to the absence of a suitable tool material, FSW of carbon steels has been reported by several groups [21-24].

Thus, in this study, an FSP technique using a suitable tool was applied to tungsten inert gas (TIG)-welds of structural SS400 steel plates to investigate the effects of surface-microstructural modification by FSP on fatigue resistance of the TIG-welded steel plates. To demonstrate improved

mechanical properties of TIG-welded steel specimens with surface-microstructural modification by FSP, TIG welds were performed on SS400 steel plates, followed by FSP on the TIG weld beads. Tensile, bending, and bending fatigue tests were conducted at room temperature (RT) for the steel specimens containing the TIG weld beads with and without FSP.

\section{Experimental procedure}


The TIG welds were produced on commercially available 5-mm-thick SS400 steel plates with automated TIG welders operating at $150 \mathrm{~A}$ and a head travel speed of $2 \mathrm{~mm} / \mathrm{s}$. Table 1 contains the nominal chemical composition (wt.\%) for SS400.

FSP was performed on TIG weld beads with a small tool containing a 12-mm-diameter shoulder and a $0.8-\mathrm{mm}$-long and 4-mm-diameter probe operating at $400 \mathrm{rpm}$ and $140 \mathrm{~mm} / \mathrm{min}$. The temperature at the FSP region increased above the alpha-gamma transformation temperature [24, 25]. FSP tools were operated with counter-clockwise rotation with $14.7 \mathrm{kN}$ in applied-stress control, and were manufactured from tungsten carbide.

Tensile specimens were prepared parallel to the TIG and FSP weld beads, and tensile tests were conducted at RT at the strain rate of $1 \times 10^{-3} \mathrm{~s}^{-1}$. Specimens deviated from the sizes and geometries dictated by American society for testing and materials standards, and their gauge thickness, width, and length were $5 \mathrm{~mm}, 4 \mathrm{~mm}$, and $20 \mathrm{~mm}$, respectively. Bending and bending fatigue specimens were prepared perpendicular to the weld beads, and their bar-type samples had dimensions of 2.7 $\mathrm{mm} \times 60 \mathrm{~mm} \times 5 \mathrm{~mm}$. The length of the support span and radius of the punch were $25 \mathrm{~mm}$ and 5 mm, respectively. The Japanese industrial standard Z2248 was used for these tests, which has been prepared based on the second edition of international organization for standardization 7438 [26]. The bending tests were performed at RT at strain rates of $5.1 \times 10^{-3} \mathrm{~s}^{-1}, 5.1 \times 10^{-4} \mathrm{~s}^{-1}$, and $5.1 \times 10^{-5}$ $\mathrm{s}^{-1}$. The bending fatigue tests were performed at RT with a sinusoidal waveform at $20 \mathrm{~Hz}$ as a function of maximum applied load between $600 \mathrm{MPa}$ and $800 \mathrm{MPa}$ with a load ratio of 0.1 . The Vickers hardness tests used a square-based diamond pyramid with a $136^{\circ}$ point angle. The applied load and force-maintaining time were $0.981 \mathrm{~N}$ and $35 \mathrm{~s}$, respectively.

Residual stresses were measured in the directions parallel and perpendicular to the weld beads using a $\mu$-X360 portable X-ray residual stress analyzer (Pulstec Industrial Co., Ltd.). Microstructures of the TIG-welded steel specimens with and without FSP were observed by optical microscopy and scanning electron microscopy (SEM) equipped with an electron backscattering 
diffraction (EBSD) pattern detector.

\section{Results and discussion}

Figure 1 shows cross-sectional optical images of TIG-welded SS400 steel plates with and without FSP. The fusion weld depth and width of the TIG-welded SS400 steel plates were about $2.5 \mathrm{~mm}$ and $6 \mathrm{~mm}$, respectively (Fig. 1(a)). The heat-affected zone (HAZ) was about $8 \mathrm{~mm}$ wide and reached the bottom of the steel plates. The FSP region was about $1 \mathrm{~mm}$ deep and $9 \mathrm{~mm}$ wide, and covered the TIG fusion weld and HAZ (Fig. 1(b)). Microstructure modification by FSP was limited to the topmost of the TIG welds.

Figure 2 shows RT stress-strain curves of the SS400 specimen and TIG-welded steel specimens with and without FSP. The TIG-welded steel specimens with and without FSP exhibited indistinct yield points, relatively high tensile strength, and similar tensile elongation compared with the SS400 specimen. The surface-microstructural modification by FSP did not remarkably influence tensile properties. On the other hand, the bending strength of the TIG-welded steel specimens with FSP was remarkably higher than that without FSP, as shown in Figure 3. The TIG weld beads with and without FSP in all specimens were in tension in bending tests. The maximum bending strength of the TIG-welded steel specimens with FSP exhibited about $1.4 \mathrm{GPa}$ at $5.1 \times 10^{-5} \mathrm{~s}^{-1}$, which was 40\% higher than that without FSP (about $1 \mathrm{GPa}$ ), as shown in Figure 3(a). Although stress-strain curves of SS400 did not depend on strain rate, those of the TIG-welded steel specimens with and without FSP were dependent on the strain rate (Fig. 3(a) and 3(b)). The bending strength of the TIG-welded steel specimens without FSP slightly increased with the increasing strain rate, while that of the TIG-welded steel specimens with FSP increased remarkably with the decreasing strain rate.

These observations indicate that the surface-microstructural modification by FSP significantly improved the slow bending-deformation resistance. The results also suggest that the 
surface-microstructural modification by FSP would improve bending fatigue resistance at relatively low applied stresses, and thus the bending fatigue of the TIG-welded steel specimens with and without FSP was investigated. Figure 4 shows three-point bending fatigue results for the TIG-welded steel specimens with and without FSP. The number of cycles to failure is plotted as a function of applied stress amplitude $\left(\left(\sigma_{\max }-\sigma_{\min }\right) / 2\right)$. In the TIG-welded steel specimens without FSP, the number of cycles to failure exhibited log-linear increase with decreasing stress amplitude (broken line). The TIG-welded steel specimens with FSP also exhibited log-linear increase of the number of cycles to failure in the stress amplitude range between 270 and $315 \mathrm{MPa}$ (solid line), and its increase rate was higher than that of the TIG-welded steel specimens without FSP, although the increase rate of the TIG-welded steel specimens with FSP decreased in the stress amplitude range between 338 and $360 \mathrm{MPa}$, and consequently the number of cycles to failure became similar to that of the TIG-welded steel specimens without FSP. FSP produced about $170 \%$ increase in the number of cycles to failure at an applied stress amplitude of $270 \mathrm{MPa}$ and about $13 \%$ increase in the stress amplitude that could be applied at $2.0 \times 10^{5}$ cycles.

These observations indicate that the surface-microstructural modification by FSP significantly improved the bending fatigue resistance. Figure 5(a) shows displacements of the bar-type specimens for the TIG-welded steel specimens with and without FSP as a function of cycle number at the minimum $(60 \mathrm{MPa})$ and maximum (600 $\mathrm{MPa})$ applied stresses, with an applied stress amplitude of $270 \mathrm{MPa}$ during the three-point bending fatigue tests as one example. The displacements of the TIG-welded steel specimens with FSP were remarkably smaller than those of the TIG-welded steel specimens without FSP at all cycle numbers and at both the minimum and maximum applied stresses. The displacement-increase rate of the TIG-welded steel specimens with FSP was also lower. These observations indicate that the surface-microstructural modification by FSP increased the bending stiffness of the bar-type specimens. Consequently, FSP produced a small flexion of the bar-type specimens at the number of cycles to failure (Fig. 5(d)) compared with the 
TIG-welded bar-type specimens without FSP (Fig. 5(b)). FSP also produced a zigzag-shaped crack (Fig. 5(e)) at the fatigue fracture start portion compared with a straight-shaped crack (Fig. 5(c)) for the TIG-welded bar-type specimens without FSP.

To investigate the origin of improvement in the bending fatigue resistance by FSP, the microstructure of the TIG-welded steel specimens with and without FSP was observed. Figure 6 shows portions of cross-sectional SEM images of TIG-welded steel specimens with and without FSP. Flat surfaces were obtained for the TIG-welded steel specimens both with and without FSP. The SEM/EBSD images of the TIG-welded steel specimens with and without FSP did not show any specific texture. The TIG-welded steel specimens without FSP consisted of coarse grains and dendrites in the region from immediately beneath to $2 \mathrm{~mm}$ below the surface, which constituted the TIG fusion weld region (Fig. 6(b) and 6(c)). Figure 6(d) shows HAZ regions $3 \mathrm{~mm}$ below the surface of the TIG-welded steel specimens without FSP, consisting of coarse grains. SEM images (not shown) obtained from the TIG fusion weld and HAZ regions indicated many $\mathrm{Fe}_{3} \mathrm{C}$ precipitations, which were almost uniformly oriented at the TIG fusion weld region and randomly oriented at the HAZ region.

On the other hand, FSP produced ultrafine microstructure consisting of grains with average grain sizes of about 1-2 $\mu \mathrm{m}$ in diameter beneath the surface (Fig. 6(f)). Figure 6(g) shows a boundary line between microstructure modified by FSP and the TIG weld region, which was $1 \mathrm{~mm}$ below the surface. In the microstructure modified by FSP around the boundary line, the ultrafine grains were mixed with grains that were elongated and slanting downward. The microstructure at $2 \mathrm{~mm}$ below the surface for the TIG-welded steel specimens with FSP (Fig. 6(h)) was similar to that at $3 \mathrm{~mm}$ below the surface for the TIG-welded steel specimens without FSP (Fig. 6(d)). This suggests that the ultrafine grains formed beneath the surface by FSP increased the bending stiffness, slow-deformation resistance, and bending fatigue resistance. In fact, the ultrafine microstructure exhibited Vickers hardness of about 2.2 GPa (Fig. 7(b)), which was higher than that of the 
TIG-welded regions, with Vickers hardness of about $2.0 \mathrm{GPa}$ (Fig. 7(a)). In comparison, the microstructure far away from the TIG-welded regions exhibited Vickers hardness of about 1.4 GPa, which is similar to that of SS400.

On the other hand, residual tensile stress would be produced in the TIG weld beads, and thus the weld part would be a weak point in the structure. Peening techniques such as laser peening [12] were performed to convert tensile stress remaining in the weld beads to compressive stress. Thus, to understand the effect of FSP on the residual tensile stress in the TIG weld beads, residual stress was measured for the TIG-welded steel specimens with and without FSP, and the results are shown in Figure 8, together with those for steel specimens only with FSP for comparison. The surface planes of the steel plates were milled, and they had residual tensile stress of about $600 \mathrm{MPa}$. The residual tensile stress at the TIG weld beads with and without FSP exhibited similar values and was lower than that at the milled planes. There was no obvious difference in the residual stress perpendicular and parallel to the TIG weld beads with or without FSP, and thus the improvement of the bending and bending fatigue properties would be explained by microstructure effects.

However, the FSP beads in the steel specimens only with FSP exhibited residual compressive stress when measured perpendicular to the FSP beads (Fig. 8(a)), although they exhibited residual tensile stress when measured parallel to the FSP beads (Fig. 8(b)). This suggests that FSP could also convert tensile stress remaining in the weld beads to compressive stress, but the conversion was not realized in the present study probably due to insufficient size combination of the FSP stir zone and the TIG weld zone.

As mentioned in the introduction, to increase the fatigue strength of weld joints, various surface treatment techniques have been studied. The number of cycles to failure of the weld joints with surface treatments such as the laser peening [12] and the shot peening [13] significantly increased with decreasing applied stress amplitude or maximum applied stress. Although fatigue-test conditions such as a load ratio and tensile strengths of structural steel plates investigated are 
different, the significant increase of the number of cycles to failure was not observed in this study, but it was obtained by further refinement in the fine-grained FSP region (not shown here). The laser peening provided increase of Vickers hardness due to work hardening in the region from immediately beneath to $0.2 \mathrm{~mm}$ below the surface and large compressive residual stress (about 400 $\mathrm{MPa}$ ) in the region from immediately beneath to $1.0 \mathrm{~mm}$ below the surface [12]. The shot peening also provided large compressive residual stress (about $400 \mathrm{MPa}$ around the surface) in the region from immediately beneath to $0.6 \mathrm{~mm}$ below the surface [13]. Thus, such the large residual stress in about $1 \mathrm{~mm}$-thick region from the surface was concluded to play a key role in increasing the fatigue strength of weld joints with these surface treatment techniques based on work hardening. This is different from the mechanism in this study that increasing the fatigue strength of weld joints is controlled by the fine-grained FSP region with about $1 \mathrm{~mm}$-thick region from the surface.

To understand effects of ultrafine grains on increasing bending fatigue resistance, microstructures before and after bending tests were observed, and the results are shown in Figure 9. Figure 9 shows cross-sectional SEM/EBSD images of TIG-welded steel specimens with and without FSP and before and after bending tests. The SEM/EBSD images did not show any considerable microstructure difference before and after bending tests for the TIG-welded steel specimens without FSP (Fig. 9(a) and 9(b)); however, the microstructure of the ultrafine grains was substantially changed from a vertically long shape before the bending tests (Fig. 9(c)) to a laterally long shape after bending tests (Fig. 9(d)) for the TIG-welded steel specimens with FSP. The laterally long ultrafine grains observed after bending tests lied in parallel to tension direction. The fine-grained FSP region indicates enhancement of grain-boundary strengthening, and consequently increase in the bending stiffness and bending strength. Such uniform deformation of ultrafine grains is suggested to enhance bending strength at low strain rate and bending fatigue resistance at low applied stress amplitude. 


\section{Conclusions}

In this study, effects of surface-microstructural modification by FSP on mechanical properties of TIG-welded SS400 steel plates were investigated. Although the tensile properties of the TIG-welded steel plates with FSP were similar to those without FSP, FSP significantly improved bending strength and bending fatigue resistance. The important findings are as follows:

1) Bending strength of the TIG-welded steel specimens with FSP exhibited about $1.4 \mathrm{GPa}$ at 5.1 $\mathrm{x} 10^{-5} \mathrm{~s}^{-1}$ at RT, which was $40 \%$ higher than that without FSP (about $1 \mathrm{GPa}$ ). The increase of bending strength for the TIG-welded steel specimens with FSP enhanced remarkably with decreasing strain rate.

2) FSP produced about $170 \%$ increase in the number of cycles to failure at an applied stress amplitude of $270 \mathrm{MPa}$, and about $13 \%$ increase in the stress amplitude that could be applied at $2.0 \times 10^{5}$ cycles during three-point bending fatigue at RT.

3) FSP produced ultrafine microstructure consisting of grains with average grain sizes of about 1-2 $\mu \mathrm{m}$ in diameter beneath the surface. The formation of such ultrafine grains beneath the surface by FSP is suggested to enhance grain-boundary strengthening, leading to increased bending stiffness, slow-deformation resistance, and bending fatigue resistance. In fact, the ultrafine microstructure exhibited Vickers hardness of about $2.2 \mathrm{GPa}$, which was higher than that of the TIG-welded regions, with Vickers hardness of about 2.0 GPa.

4) Microstructures of the ultrafine grains were considerably changed, from a vertically long shape before the bending tests to a laterally long shape after bending tests for the TIG-welded steel specimens with FSP. The laterally long ultrafine grains observed after bending tests lied in parallel to tension direction. The uniform deformation of ultrafine grains is suggested to enhance bending strength at low strain rate and bending fatigue resistance at low applied stress amplitude. 


\section{Acknowledgements}

The authors (R. Ueji and H. Fujii) wish to acknowledge the financial support of the Japan Science and Technology Agency (JST) under Collaborative Research Based on Industrial Demand, "Heterogeneous Structure Control: Towards Innovative Development of Metallic Structural Materials," the Global COE Programs of the Ministry of Education, Sports, Culture, Science and Technology, and a Grant-in-Aid for Science Research from the Japan Society for Promotion of Science and Technology of Japan.

\section{References}

[1] Ma ZY, Pilchak AL, Juhas MC, Williams JC. "Microstructural refinement and property enhancement of cast light alloys via friction stir processing”, Scr Mater 2008;58:361.

[2] Darras BM, Khraisheh MK, Abu-Farha FK, Omar MA. "Friction stir processing of commercial AZ31 magnesium alloy", J Mater Proc Tech 2007; 191:77.

[3] Su JQ, Nelson TW, Sterling CJ. "Friction stir processing of large-area bulk UFG aluminum alloys", Scr Mater 2005;52:135.

[4] Nakata K, Kim YG, Fujii H, Tsumura T, Komazaki T. "Improvement of mechanical properties of aluminum die casting alloy by multi-pass friction stir processing", Mater Sci Eng A - Struct $2006 ; 437: 274$.

[5] da Silva J, Costa JM, Ferreira JM. "Fatigue behavior of AA6082-T6 MIG welded butt joints improved by friction stir processing", Mater Design 2013;51:315.

[6] Fuller CB, Mahoney MW. "The effect of friction stir processing on 5083-H321/5356 Al arc welds: Microstructural and mechanical analysis", Metall Mater Trans A 2006;37:3605.

[7] Abdullah A, Malaki M, Eskandari A. "Strength enhancement of the welded structures by ultrasonic peening", Mater Design 2012; 38:7.

[8] Zhao X, Wang D, Huo L. "Analysis of the S-N curves of welded joints enhanced by ultrasonic 
peening treatment", Mater Design 2011;32:88.

[9] Yin D, Wang D, Jing H, Huo L. "The effect of ultrasonic peening treatment on the ultra-long life fatigue behavior of welded joints", Mater Design 2010;31:3299.

[10] Wang T, Wang D, Huo L, Zhang Y. "Discussion on fatigue design of welded joints enhanced by ultrasonic peening treatment (UPT)", Inter J Fatigue 2009;31:644.

[11] Lixing H, Dongpo W, Yufeng Z, Junmei C. "Investigation on improving fatigue properties of welded joints by ultrasonic peening method", Welding in the World 2001;45:12.

[12] Sakino Y, Sano Y, Sumiya R, Kim YC. "Major factor causing improvement in fatigue strength of butt welded steel joints after laser peening without coating”, Sci Tech Weld Joining $2012 ; 17: 402$.

[13] Naito A, Takakuwa O, Soyama H. "Development of peening technique using recirculating shot accelerated by waterjet", Mater Sci Tech 2012;28:234.

[14] Lah NAC, Ali A, Ismail N, Chai LP, Mohamed AA. "The effect of controlled shot peening on fusion welded joints", Mater Design 2010;31:312.

[15] Lee WB, Kim GH, Moon KI, Lee Y. "Strengthening dual phase steel welds by shot peening”, ISIJ Inter 2009;49:1972.

[16] Li D, Chen HN, Xu H. “Comparative responses of welded joints to surface mechanical attrition treatment and shot peening", Surf Eng 2009;25:15.

[17] Moriyama M, Nagano T, Kawagoishi N, Takaki S, Nagashima E. "Effect of shot peening on fatigue strength of 18\%Ni maraging steel”, JSME Inter Series A 2001;44:301.

[18] Weich I. "Edge layer condition and fatigue strength of welds improved by mechanical post-weld treatment", Welding in the World 2011;55:3.

[19] Weich I, Ummenhofer T, Nitschke-Pagel T, Chalandar HE, Dilger K. "Fatigue behavior of welded high-strength steels after high frequency mechanical post-weld treatments", Welding in the World 2009;53:322. 
[20] Lobanov LM, Kyr’yan VI, Knysh VV. “Enhancement of the service life of welded metal structures by high-frequency mechanical peening”, Mater Sci 2006;42:54.

[21] Thomas WM, Threadgill PL, Nicholas ED. "Feasibility of friction stir welding steel", Sci Tech Weld Join 1999;4:365.

[22] Lienert TJ, Stellwag WL, Grimmett BB, Warke RW. "Friction stir welding studies on mild steel", Weld J 2003;8:1s.

[23] Reynolds AP, Tang W, Posada M, DeLoach J. "Friction stir welding of DH36 steel”, Sci Tech Weld Join 2003;8:455.

[24] Fujii H, Cui L, Tsuji N, Maeda M, Nakata K and Nogi K. "Friction stir welding of carbon steels", Mater. Sci. Eng. A, 2006, 429: 50.

[25] Cui L, Fujii H, Tsuji N and Nogi K. "Friction stir welding of a high carbon steel", Scripta Mater., 2007, 56: 637.

[26] Japanese Industrial Standard Z 2248. Metallic materials-Bend test, JAPAN; 2006.

Table 1. Nominal composition (weight \%) of SS400.

\begin{tabular}{|l|l|l|l|l|l|l|}
\hline Alloy & C & Si & Mn & P & S & Fe \\
\hline SS400 & 0.16 & 0.16 & 0.67 & 0.014 & 0.006 & balance \\
\hline
\end{tabular}


Figure captions:

Fig. 1. Cross-sectional optical images of TIG-welded SS400 steel plates (a) without and (b) with FSP. The SS400 steel plates were $5 \mathrm{~mm}$ in thickness.

Fig. 2. Stress-strain curves of a SS400 steel specimen and TIG-welded steel specimens with and without FSP obtained in tensile tests at RT at the strain rate of $1 \times 10^{-3} \mathrm{~s}^{-1}$. The tensile axes were parallel to the rolling direction of SS400 steel plates, the TIG-weld direction, and the FSP-travel direction.

Fig. 3. Stress-strain curves of a SS400 steel specimen and TIG-welded steel specimens with and without FSP obtained in bonding tests at RT at the strain rate of (a) $1 \times 10^{-5} \mathrm{~s}^{-1}$ and (b) $1 \times 10^{-3} \mathrm{~s}^{-1}$. The TIG-welded regions with and without FSP were in tension.

Fig. 4. Three-point bending fatigue results at RT for the TIG-welded steel plates with and without FSP.

Fig. 5. (a) Displacement variety of the TIG-welded steel plates with and without FSP with cycle number at the minimum (60 MPa) and maximum (600 MPa) applied stresses and at an applied stress amplitude of $270 \mathrm{MPa}$ in bending fatigue tests at RT. Optical images of the bar-type specimens without ((b) and (c)) and with FSP ((d) and (e)) at their numbers of cycles to failure.

Fig. 6. Cross-sectional SEM images of TIG-welded steel specimens (a) without and (e) with FSP. SEM/EBSD images of the TIG-welded steel specimens without FSP (b) just beneath, (c) $2 \mathrm{~mm}$ below, and (d) $3 \mathrm{~mm}$ below the surface. Those of the TIG-welded steel specimens with FSP (f) just 
beneath, (g) $1 \mathrm{~mm}$ below, and (h) $2 \mathrm{~mm}$ below the surface.

Fig. 7. Hardness variety with distance from weld center and with depth below the surface for the TIG-welded steel specimens (a) without and (b) with FSP.

Fig. 8. Residual-stress variety with distance from weld center for TIG-welded steel specimens with and without FSP, together with those for steel specimens only with FSP for comparison. Residual stresses were measured (a) perpendicular and (b) parallel to the weld beads.

Fig. 9. Cross-sectional SEM images of TIG-welded steel specimens without ((a) and (b)) and with ((c) and (d)) FSP before ((a) and (c)) and after ((b) and (d)) bending tests at the strain rate of $1 \mathrm{x}$ $10^{-4} \mathrm{~s}^{-1}$. 

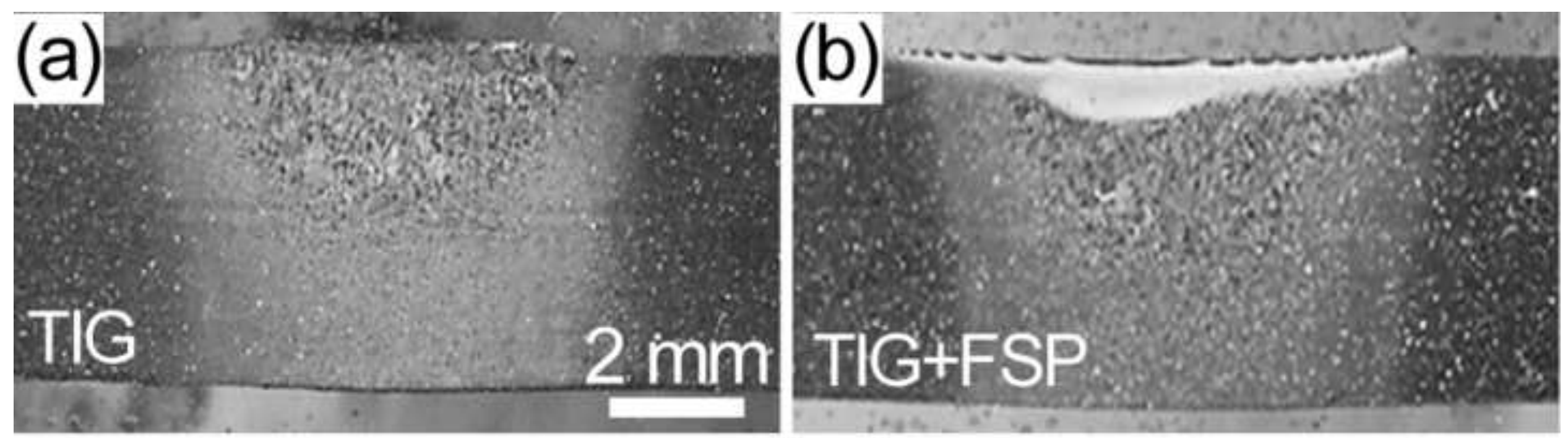

\section{Figure 1}




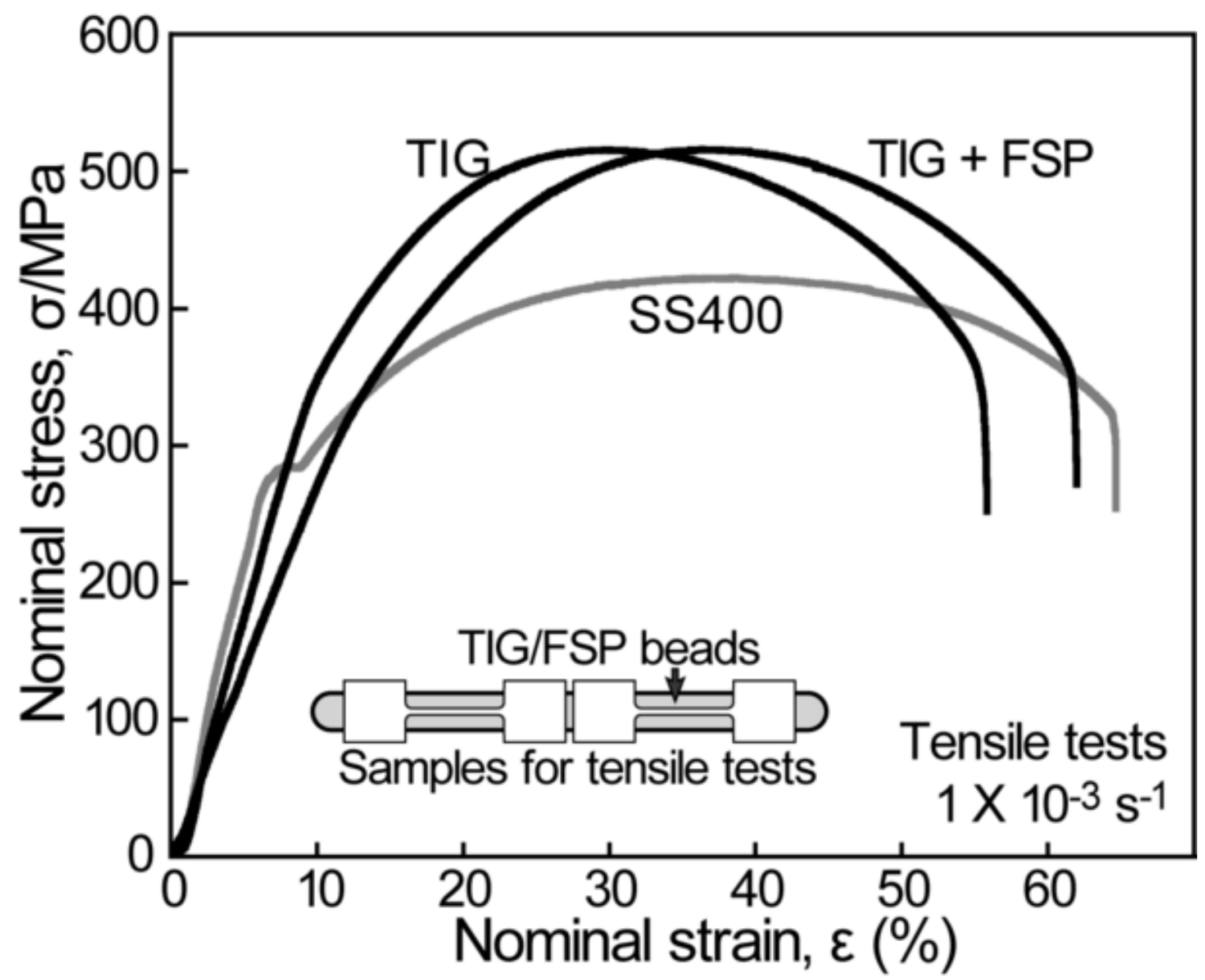

Figure 2 


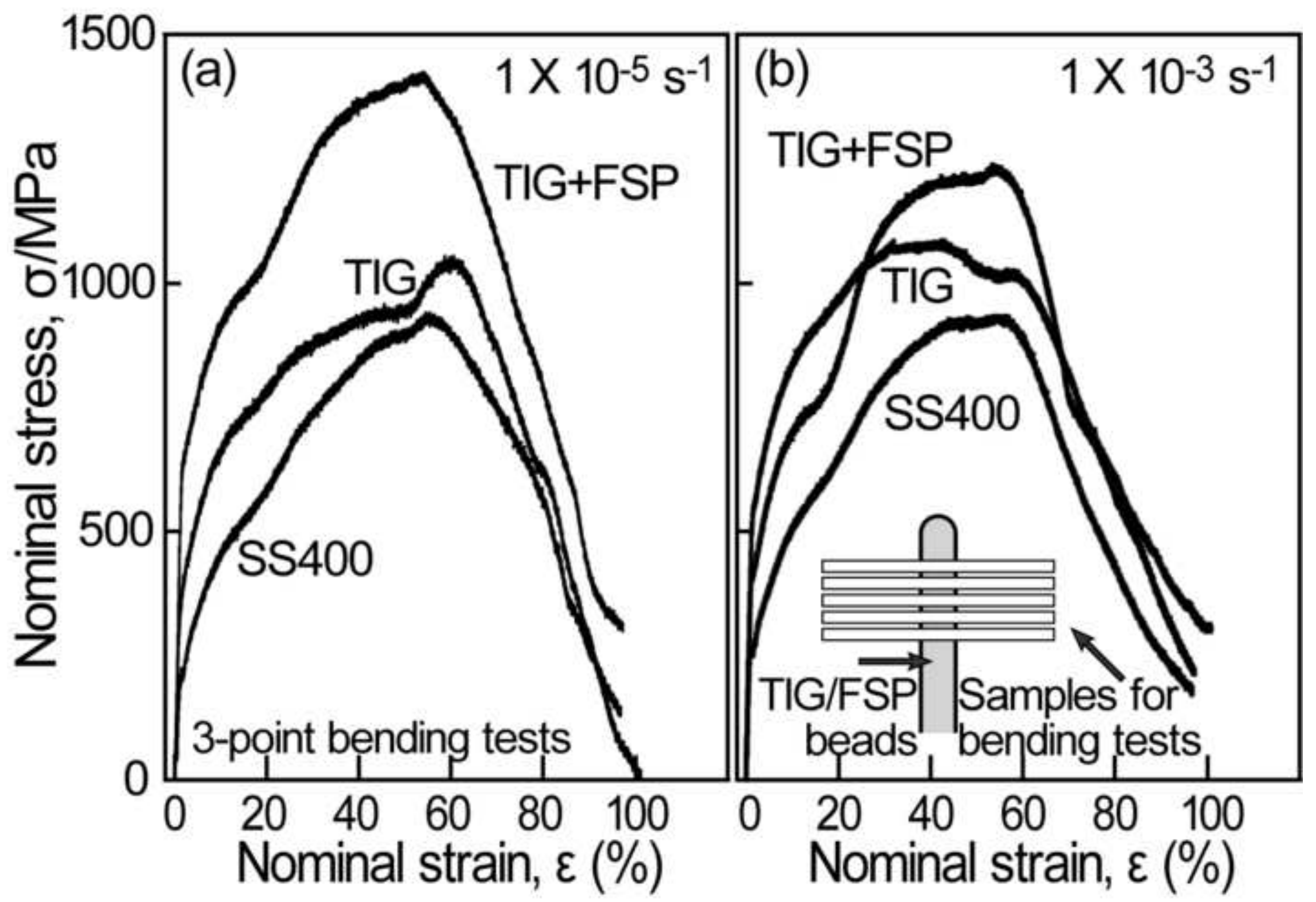

Figure 3 


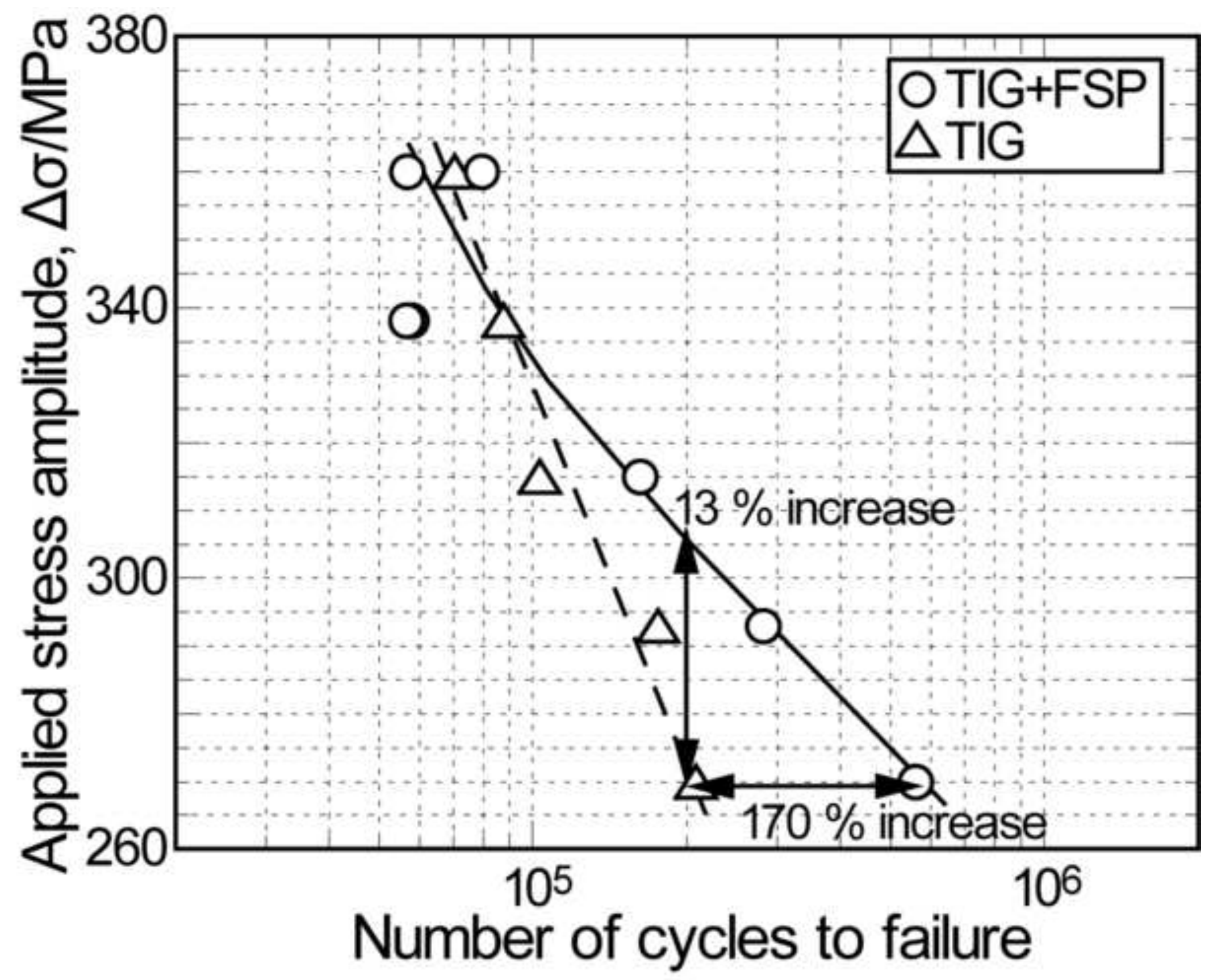

Figure 4 


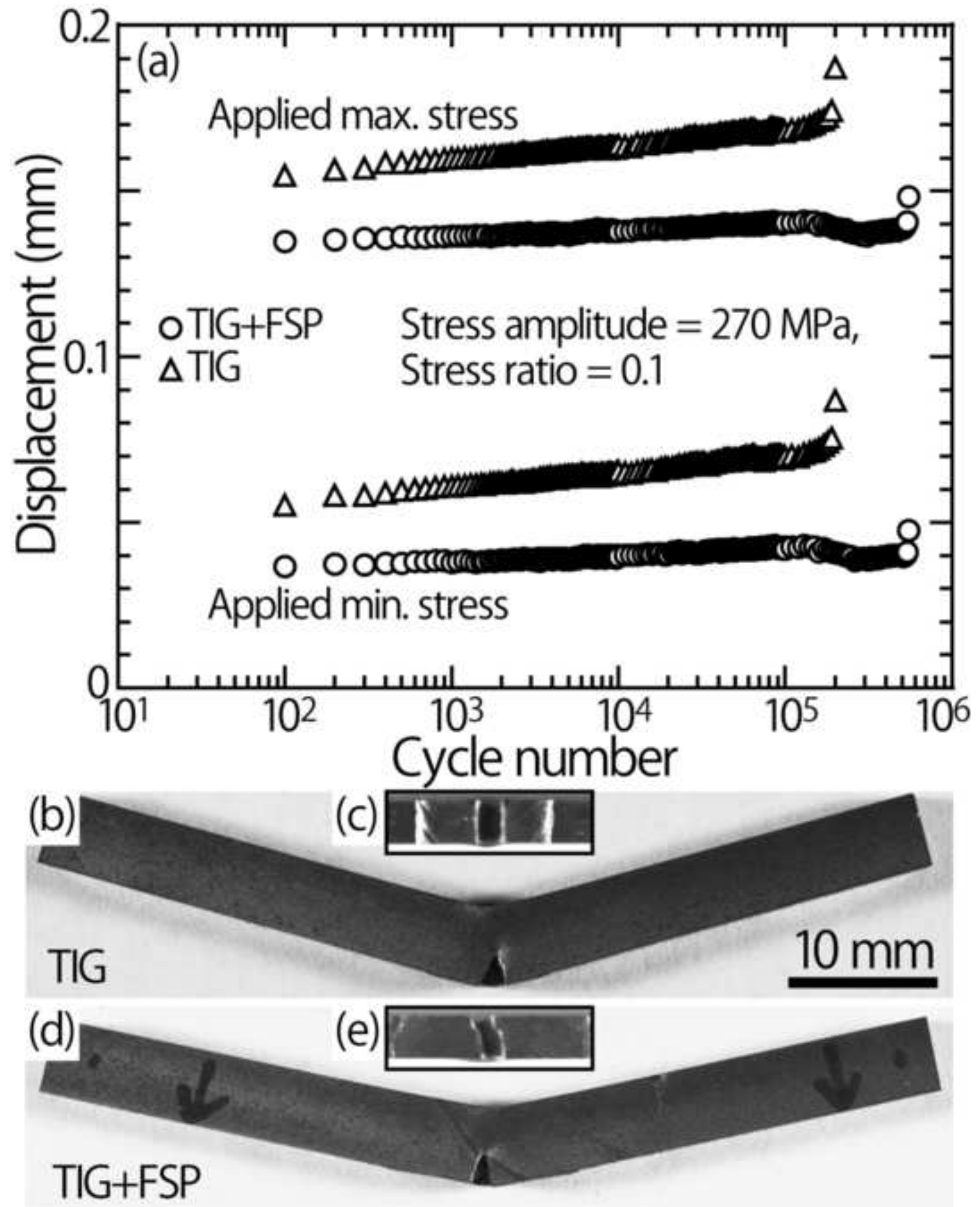

Figure 5 


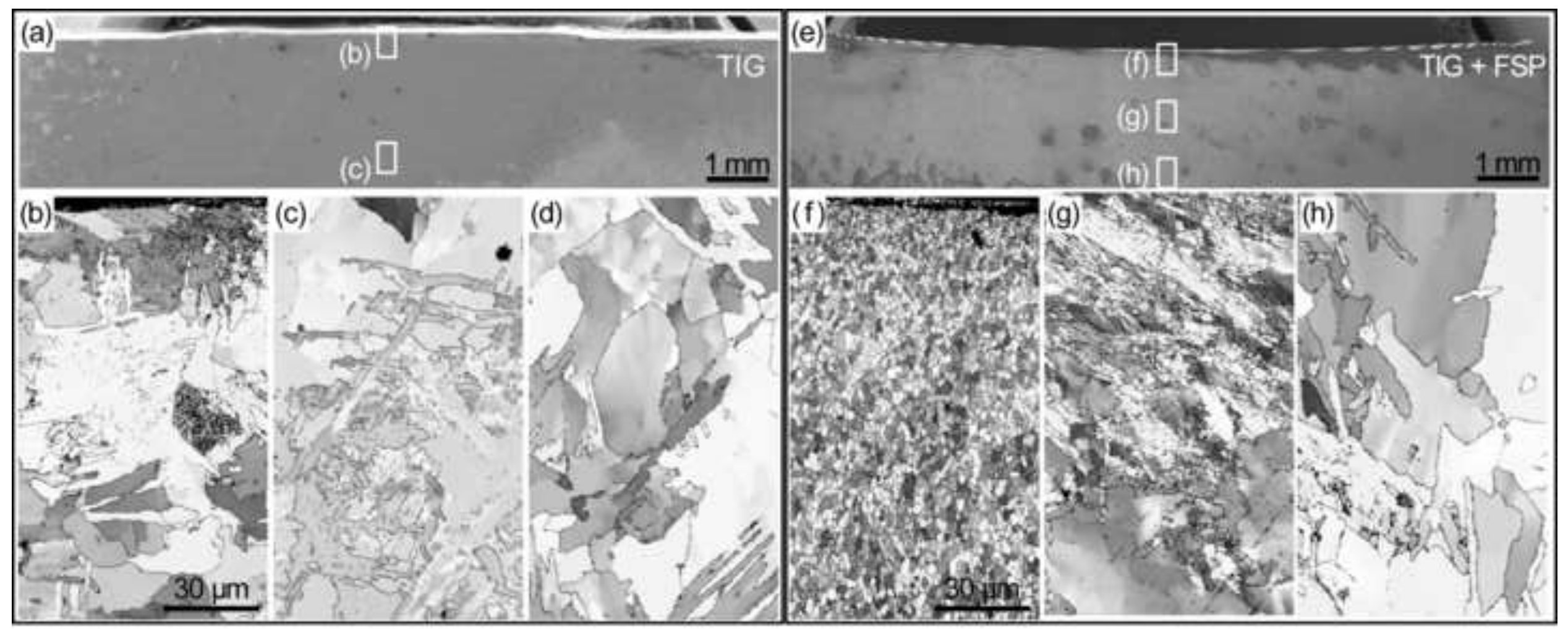

Figure 6 


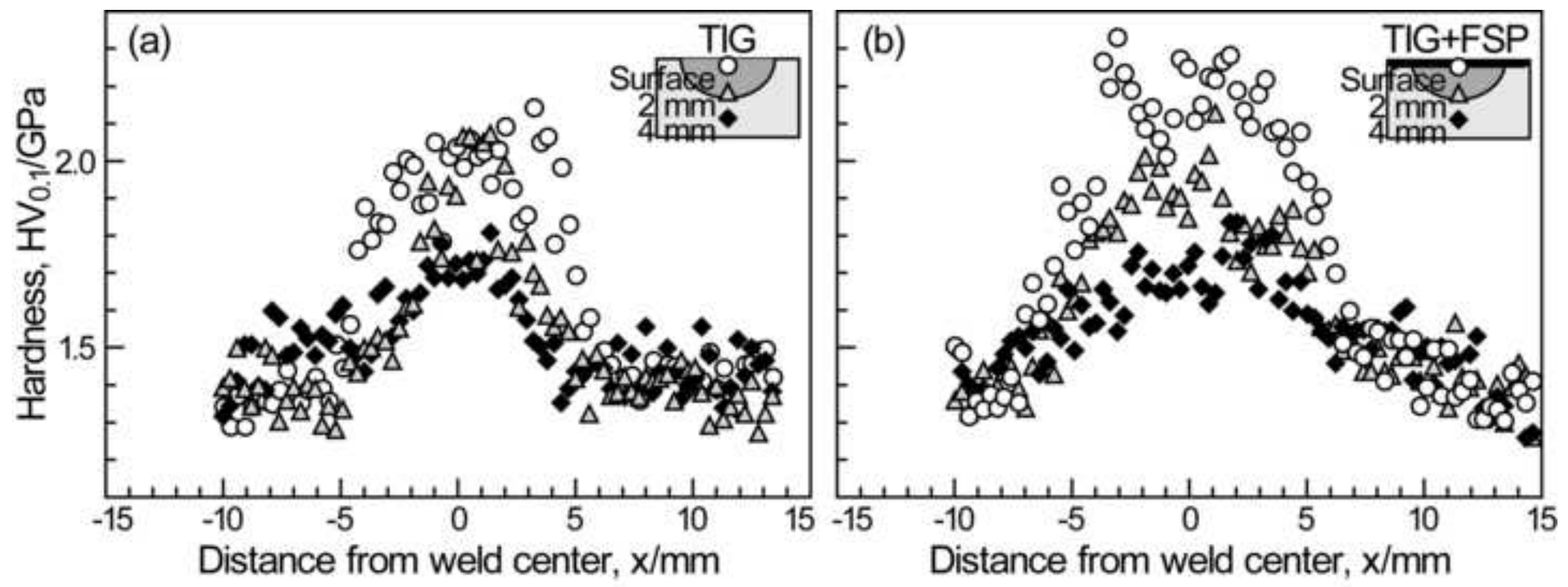

Figure 7 


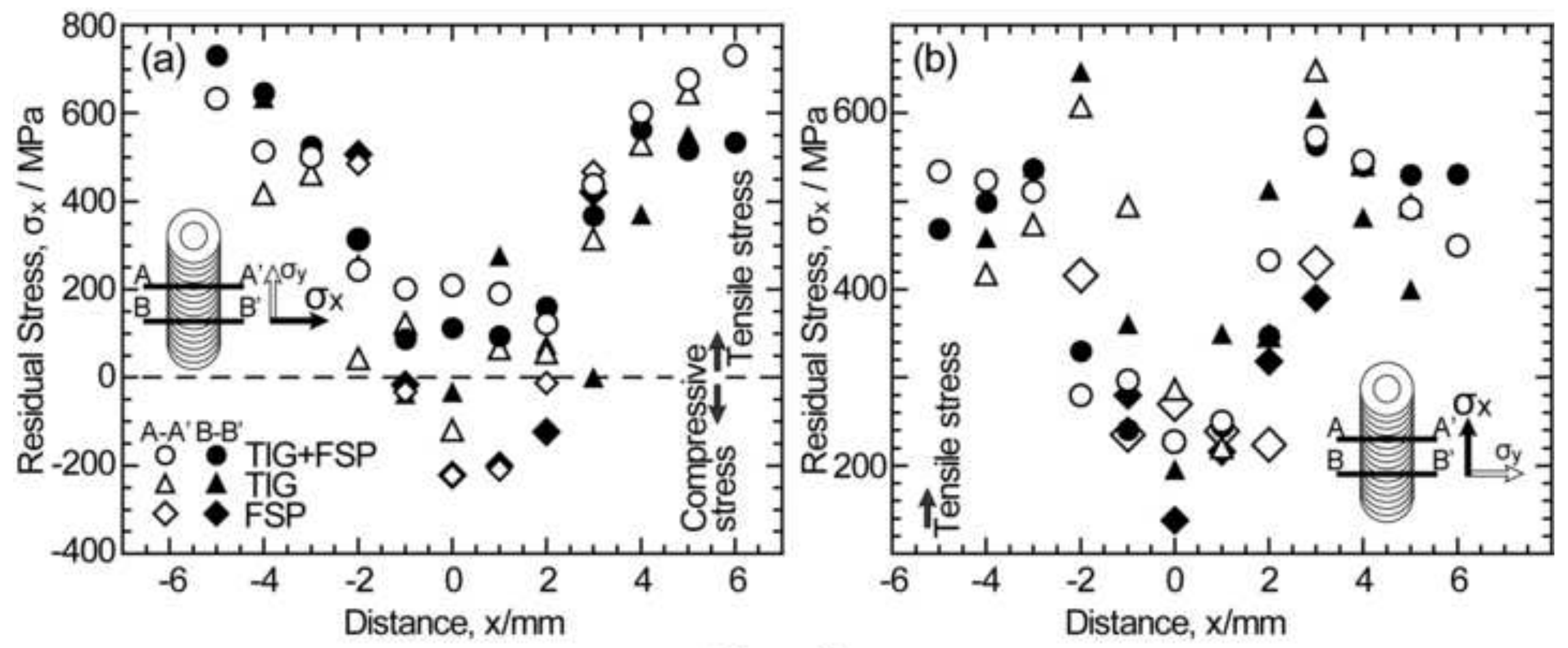

Figure 8 

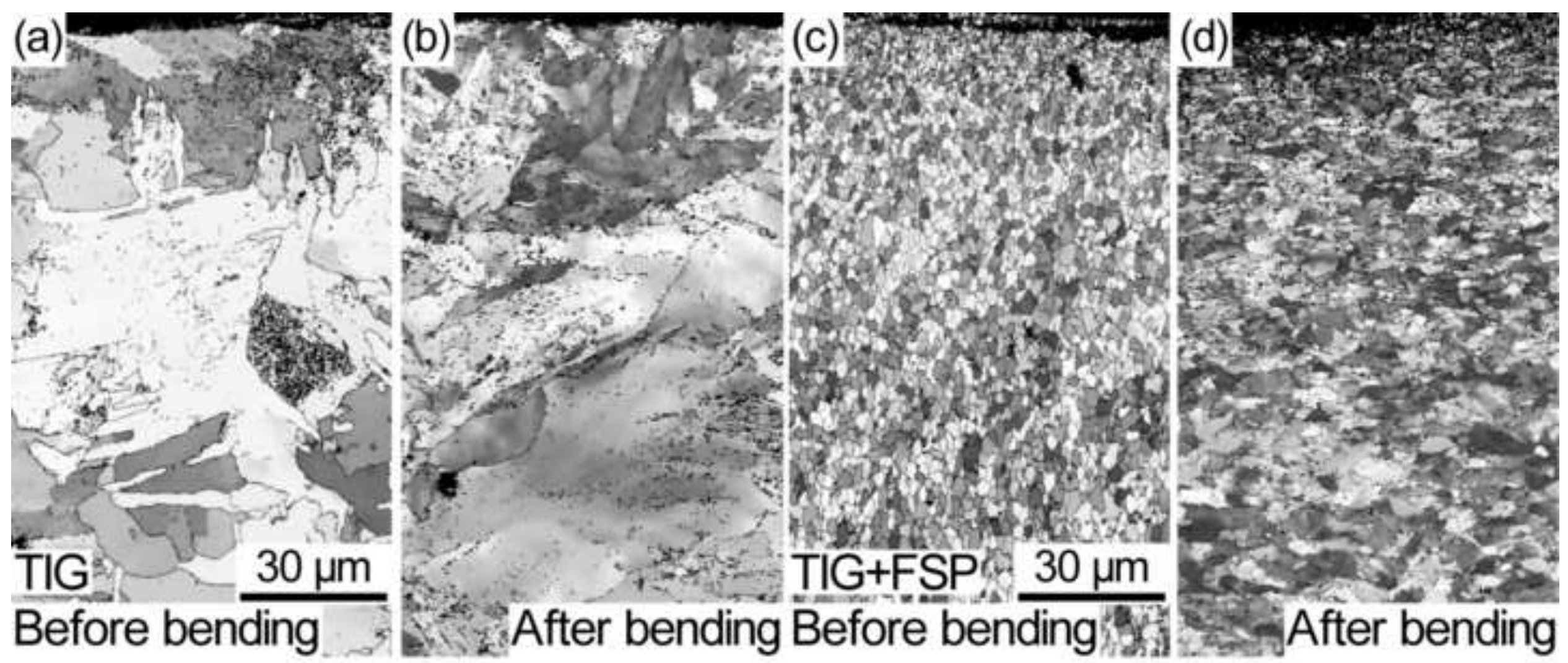

A

Figure 9 